This is the peer reviewed version of the following article: Harju, T., Kivekäs, I., Numminen, J. and Rautiainen, M. (2018). The effect of inferior turbinate surgery on ear symptoms. The Laryngoscope, 128(3): 568-572, which has been published in final form at https://doi.org/10.1002/lary.26823. This article may be used for non-commercial purposes in accordance with Wiley Terms and Conditions for Self-Archiving.

\title{
The effect of inferior turbinate surgery on ear symptoms
}

Teemu Harju, MD; Ilkka Kivekäs, MD, PhD; Jura Numminen, MD, PhD; Markus

Rautiainen, MD, PhD

From the Department of Otorhinolaryngology, Tampere University Hospital, Tampere,

Finland

Running title: Turbinate surgery and ear symptoms

Conflicts of interest: None

Financial disclosures: The authors received no financial support for the research, authorship, and/or publication of this article.

\section{Corresponding author:}

Teemu Harju, MD, Department of Otorhinolaryngology, Tampere University Hospital, Teiskontie 35, 33521 Tampere, Finland

E-mail: harjtee@gmail.com 


\section{ABSTRACT}

Objective: The aim of this placebo-controlled study was to evaluate the effect of various inferior turbinate surgery techniques on Eustachian tube dysfunction-related symptoms. Study Design: Outcomes were evaluated using the Eustachian Tube Dysfunction Questionnaire (ETDQ-7) and tympanometry results.

Methods: A total of 72 consecutively blinded and randomized adult patients with enlarged inferior turbinates due to persistent year-round rhinitis underwent either a radiofrequency ablation, diode laser, microdebrider-assisted inferior turbinoplasty, or sham surgery procedure. Assessments were conducted prior to surgery and three months subsequent to the surgery.

Results: In the evaluation of all patients, radiofrequency ablation, microdebrider-assisted inferior turbinoplasty, and sham surgery procedures decreased the Eustachian Tube Dysfunction Questionnaire total score significantly. In a three-way analysis of covariance, there were no significant differences in the results between sham surgery and any of the active treatment procedures. Allergic sensitization, sex, and age had no effect on the results either. There were no significant changes in the pre- and postoperative amounts of abnormal tympanometry curves or in the pre- and postoperative tympanometric peak pressure values in the actively treated patients or in the sham surgery group.

Conclusion: The improvement of Eustachian tube dysfunction-related symptoms due to surgery of the anterior half of the inferior turbinate was found to be equal to placebo. The findings of this study do not support the use of reduction of the anterior half of the inferior turbinate as a sole procedure intended to treat the ear symptoms assessed by the ETDQ-7 questionnaire. 
Key Words: Eustachian tube dysfunction, symptoms, nasal obstruction, inferior turbinate surgery, placebo-controlled, randomized

Level of Evidence: $1 \mathrm{~b}$

\section{INTRODUCTION}

Inferior turbinate enlargement is one of the main causes of nasal obstruction. Bilateral inferior turbinate swelling is due to allergic or nonallergic rhinitis. Intranasal corticosteroids are the most important medicine group in the treatment of rhinitis. When medical therapy for enlarged inferior turbinates fails, turbinate surgery can be performed. ${ }^{1,2}$

Eustachian tube dysfunction (ETD) is a common condition in otorhinolaryngology practice. Symptoms include fullness or clogging of the ears, pain or discomfort, hearing loss, tinnitus, dizziness, and an inability to rapidly equilibrate middle ear pressure..$^{3,4}$ ETD is in most cases caused by mucosal inflammation and edema in the Eustachian tube (ET) lumen. ${ }^{5}$ It has been presented that sinonasal diseases, such as nasal viral upper respiratory tract infections, ${ }^{6}$ allergic rhinitis, ${ }^{7}$ and chronic rhinosinusitis, ${ }^{8}$ can cause mucosal inflammation which leads to ETD. However, the relationship between chronic nasal obstruction caused by inferior turbinate enlargement and ETD and the effect of turbinate surgery on ETD have not been evaluated previously in the literature.

Many subjective and objective methods have been reported for measuring ET function, including otoscopic appearance, the Valsalva and Toynbee tests, tympanometry, tubomanometry, ${ }^{9}$ and sonotubometry. ${ }^{10}$ However, due the complexity of the functional 
anatomy and physiology of the ET, there is still a lack of a diagnostic "gold standard" for obstructive ET dysfunction. ${ }^{4,11}$

McCoul et al. have developed the Eustachian Tube Dysfunction Questionnaire (ETDQ-7), which is a validated, organ-specific tool for the assessment of symptoms in ETD. ${ }^{4}$ Its usefulness has been shown in recent studies. ${ }^{9,12,13}$ So far, it has not been used in the evaluation of the relationship between ETD and functional problems of the nose.

The aim of this placebo-controlled study was to evaluate the effect of various inferior turbinate surgery techniques, such as radiofrequency ablation (RFA), diode laser, and microdebrider-assisted inferior turbinoplasty (MAIT), on ETD-related symptoms using the ETDQ-7 as an assessment method.

\section{MATERIALS AND METHODS}

The study was carried out at Tampere University Hospital, Tampere, Finland, between February 2014 and November 2016. The institutional review board approved the study design (R13144) and all patients provided written, informed consent. A total of 76 consecutive adult patients with enlarged inferior turbinates due to persistent year-round rhinitis were enrolled in this study. The patients presented symptoms of bilateral nasal obstruction related to inferior turbinate congestion that had not responded to a three-month trial of appropriate treatment with topical corticosteroids. Patients with significant nasal septum deviation affecting the nasal valve region, internal/external valve collapse/stenosis, chronic rhinosinusitis with or without polyposis, previous nasal surgery, sinonasal tumor, Ménière's disease, previous ear surgery, severe systemic disorder, severe obesity, and malignancy were excluded. 
Cone-beam computed tomography (CBCT) (Planmeca Max, Planmeca, Helsinki, Finland) was used to exclude patients with chronic rhinosinusitis from the study. Serum-specific $\lg E$ level measurements were used to identify the patients with an allergic sensitization. Allergic sensitization was defined as a specific $\lg \mathrm{E}>0.35$ for any common airborne allergen (cat, dog, horse, birch, grass, mugwort, D. pteronyssinus, and molds).

The definition of inferior turbinate enlargement was based on persistent bilateral symptoms, a finding of bilateral swelling of the inferior turbinates in nasal endoscopy, and the evident shrinking of both turbinates in a decongestion test. The nasal response to the topical vasoconstrictor $0.5 \%$ xylometazoline hydrochloride (Nasolin, Orion, Finland) in both nasal cavities 15 minutes before obtaining the second measurement was evaluated objectively using acoustic rhinometry (Acoustic rhinometer A1, GM instruments Ltd, Kilwinning, UK). An improvement of less than 30\% in anterior nasal cavity volume (V2$5 \mathrm{~cm}$ ) - the most sensitive measure of change in mucosal swelling during decongestion ${ }^{14}$ - in one or both nasal cavities was considered normal, and those patients were excluded from the study. The limit value of $30 \%$ was chosen according to previous literature. ${ }^{15,16,17}$

Patients were consecutively randomized into active treatment groups (RFA, diode laser, MAIT) and a sham surgery group using the Minim program, which is a free MS-DOS program that randomizes patients into treatment groups by the method of minimization.

The surgical treatment was performed in similar circumstances for all the groups in the day surgery department of the hospital's ENT clinic. All surgical procedures were performed by the same surgeon (T.H). The staff of the day surgery section was instructed to avoid any kind of communication - before and during the operation, as well as during the 
postoperative care - that might reveal the group of the patient. All the alternative surgical devices were available in the operation room. The procedures were carried out under local anesthesia with patients' eyes covered.

First, the inferior turbinates were topically anesthetized using cotton strips with a mixture of lidocaine $40 \mathrm{mg} / \mathrm{ml}$ (Lidocain, Orion, Finland) and $2-3$ drops of epinephrine $0.1 \%$ in $5-10 \mathrm{ml}$ of lidocaine. The local anesthetic (Lidocain $10 \mathrm{mg} / \mathrm{ml} \mathrm{c}$. adrenalin, Orion, Finland) was then applied to the medial portions of the inferior turbinates. All the procedures were performed under the direct vision of a straight, 4 mm-diameter, 0-degree endoscope (Karl Storz, Germany). In all the groups with different techniques, the treatment was given to the medial side of the anterior half of the inferior turbinate. Nasal packing (Ivalon, Fabco, New London, Connecticut) was applied only if active bleeding developed during the surgery.

The RFA treatment was carried out with a radiofrequency generator (Sutter RF generator BM-780 II, Freiburg, Germany). The "Binner" bipolar needle electrode was inserted into the medial submucosal tissue of the inferior turbinate. The upper and lower parts of the anterior half of the inferior turbinate were treated for 6 sec at 10W output power in three areas.

The diode laser treatment was given with a diode laser (FOX Laser, A.R.C. LASER GmbH, Nuremberg, Germany). The settings were as follows: wavelength of $980 \mathrm{~nm}$, output power of $6 \mathrm{~W}$ in continuous-wave mode, and laser delivery by a $600 \mu \mathrm{m}$ fiber using "contact" mode. Four parallel stripes were made on the mucosa by drawing the fiber from the posterior to the anterior direction along the medial edge of the inferior turbinate. 
In the MAIT treatment, a $2.9 \mathrm{~mm}$-diameter rotatable microdebrider tip (Medtronic Xomed, Jacksonville, FL, USA) was firmly pushed towards the turbinate bone until it pierced the mucosa of the anterior face of the inferior turbinate. Next, a submucosal pocket was dissected by tunneling the elevator tip in an anterior to posterior and superior to inferior sweeping motion. Once an adequate pocket had been created, resection of the stromal tissue was carried out by moving the blade back and forth in a sweeping motion, with the system set at $3000 \mathrm{rpm}$ using suction irrigation.

In the sham surgery procedure, small nasal mucosal biopsies for histological and cilia analysis were first taken from the anterior medial portions of the inferior turbinates, causing minor bleeding. Next, the radiofrequency tissue ablation device was turned on repeatedly near the patient, but without the needle electrodes of the device touching the patient; the patient could only hear the acoustic tone of the device. During this sound deception, a suction tube and a nasal endoscope were moved lightly in both sides of the nose for a couple of minutes in order to convince the patient that they had undergone surgery.

All the patients were evaluated prior to surgery and three months subsequent to the surgery. All clinical examinations were performed by the same examiner (T.H.) who was also the operator and not blinded to the patients' groups. The patients filled the seven-item Eustachian Tube Dysfunction Questionnaire (ETDQ-7). During the control visits, the patients filled the questionnaire before meeting the examiner. The ETDQ-7 consists of seven questions with a seven-item Likert scale, with a response of 1 indicating no problem and 7 indicating a severe problem. The total score is divided by 7 to give an overall score ranging from 1.0 to $7.0 .{ }^{4}$ The questions comprising the ETDQ-7 are shown in Table 1. Tympanometry was also performed. The tympanometry curves were classified as follows: 
Type A, normal Eustachian tube function; Type B, flat tympanogram, characteristic of the presence of fluid in the middle ear or eardrum perforation; and Type $C$, peak at very negative pressure $(<-150 \mathrm{dPa})$, which may be indicative of eardrum retraction. Tympanometric peak pressure (TPP) - that is, the peak admittance in the tympanogram and an indirect measurement of middle ear pressure - was also documented.

IBM SPSS Statistics 22.0 was used for the statistical analyses. All the non-parametric data was statistically processed using the Wilcoxon Signed Rank test. The Chi-Squared test was used in the evaluation of tympanometry curves. The effects of multiple factors were evaluated using a three-way analysis of covariance (ANCOVA).

\section{RESULTS}

Of the 76 patients enrolled in the study, four withdrew from the study before the operation took place. A total of 72 patients underwent surgery and were finally included in the study. The patients' characteristics are described in Table 2 . Some $45 \%$ of the patients had a preoperative ETDQ-7 total score of $1.0-1.9,33 \%$ had a score of $2.0-2.9$, and $22 \%$ had a score of 3.0 or more (range 3.1-4.4).

In the active treatment groups, there were abnormal tympanometry curves in six (five type B and one type $C$ ) ears preoperatively and seven (six type B and one type C) ears postoperatively. The difference was not statistically significant. In the sham surgery group, there was an abnormal tympanometry curve in only one ear (type C) preoperatively, and there were no abnormal findings postoperatively. This difference was not significant either. 
There were no significant changes in preoperative and postoperative TPP values among either the actively treated patients or the sham surgery patients (Table 3).

The results of the Eustachian Tube Dysfunction Questionnaire-7 (ETDQ-7) are shown in Table 4. In the evaluation of all patients, RFA, MAIT, and sham surgery procedures decreased the total score significantly. When only patients with a preoperative score 2.0 or more were evaluated, all the active treatment procedures decreased the total score significantly.

A three-way ANCOVA was run on the sample of 72 patients to examine the effect of sex, allergy status, and procedure group on the ETDQ-7 score change. Age was added to the model as a continuous covariate. In the evaluation of all patients, none of the factors had a significant individual main effect on the change in ETDQ-7 total score. There were no significant differences in the change in ETDQ-7 total score between the procedure groups, nor were there significant differences in the results between the sham surgery and any of the active treatment procedures. Allergic sensitization, sex, and age had no effect on the results either. The analysis was repeated for the patients with a preoperative total score 2.0 or more, and the same results were found.

\section{DISCUSSION}

In previous studies, the relationship between ETD and sinonasal factors has been evaluated using various methods, including symptom questions, ${ }^{7,18}$ tympanometry, ${ }^{19,20}$ and the Toynbee and Valsalva tests. ${ }^{21}$ In order to carry out a placebo-controlled study, it is suitable to use a validated questionnaire if possible. In the present study, the relationship 
between nasal obstruction and ETD-related symptoms was evaluated using the ETDQ-7, which is the only patient-reported outcomes tool to have undergone initial outcome studies. It is an organ-specific instrument for the assessment of symptoms. It can provide a more precise estimate of a disease burden and may yield information not readily identified by traditional clinical methods. ${ }^{4}$

The effect of sinonasal procedures and therapies on ET function has been evaluated in a few previous studies. Low and Willatt evaluated the relationship between middle ear pressure and a deviated nasal septum. They found out that middle ear pressure ipsilateral to the obstructed nasal passage was negatively correlated to the degree of asymmetry of the patencies of the two nasal passages. Middle ear pressure improved in both ears after septal surgery. They postulated that post-nasal airflow turbulence associated with a deviated nasal septum may lead to Eustachian tube dysfunction. ${ }^{19}$ Deron et al., in turn, found out that correction of the septal deviation improved the passive opening pressure of the Eustachian tube on the deviated side similarly to the non-deviated side. ${ }^{22}$ In a retrospective study by Stoikes et al., symptoms of ET were found to improve or resolve in the majority of patients undergoing endoscopic sinus surgery. ${ }^{18}$ In their randomized, prospective, placebo-controlled trial, Gluth et al. evaluated the efficacy of nasal steroid spray in treating the tympanometric signs and symptoms of ETD. They found no statistically significant difference in the normalization of abnormal tympanometric signs or in the overall poststudy symptom score between the active treatment arm and placebo. ${ }^{23}$

In the present study, the effect of inferior turbinate surgery on ETD-related symptoms was evaluated for the first time. The symptoms were found to improve due to inferior turbinate procedures. However, sham surgery improved the symptom score as effectively as real 
surgery. Furthermore, in the subgroup with more preoperative ear symptoms, there were no significant differences in the ETDQ-7 total score changes between the active treatments and the sham surgery. In addition, there were no significant changes in the pre- and postoperative amounts of abnormal tympanometry curves or in the pre- and postoperative TPP values among actively treated patients and the sham surgery patients. Possible changes in TPP values may have indicated minor changes in the middle ear pressure as a result of the operation. The lack of improvement in TPP values in the active treatment group suggests that the reduction of the anterior part of the inferior turbinate does not have even a minor effect on ET function. It is likely that in chronic inferior turbinate enlargement, the nasal mucosal edema - which can originally be caused by environmental allergens or non-allergic, non-specific triggers - can expand to the nasopharyngeal ET orifice, disturbing ET function. Based on the present study, the surgical treatment of the anterior part of the inferior turbinate did not have any real effect on the nasopharyngeal ET orifice and possible ETD.

The internal nasal valve area is the narrowest portion of the upper nasal airway, and the anterior portion of the inferior turbinate is the predominant structure in this part of the nose; therefore, it plays a major role in nasal obstruction. ${ }^{2,24}$ Surgical treatment of the anterior part of the inferior turbinate has been found to be effective in decreasing nasal obstruction. ${ }^{25}$ The posterior part of the turbinate, which is anatomically located very close to ET orifice, was not operated on in the present study. The idea of this study was also to compare the efficacy of various inferior turbinate surgery techniques in the treatment of the problem. In order to make the procedures as comparable as possible we treated the same length of the turbinate with every technique. The easiest way to guarantee that was to limit 
the operation to the anterior part of the inferior turbinate because in some cases it can be difficult to operate the posterior part of the turbinate under local anesthesia.

In the present study, the patients' main problem was nasal obstruction. Ear symptoms were not their major concern in the first place. The aim of this study was to examine possible ETD-related symptoms among the patients and the effect of inferior turbinate surgery on the symptoms. A recent consensus statement defining ETD agreed that to diagnose dilatory Eustachian tube dysfunction, patient-reported symptoms should go together with evidence of negative pressure in the middle ear. ${ }^{26}$ In the present study, more than half of the patients had an ETDQ-7 score of 2.0 or more, and more than one fifth of the patients had a score of 3.0 or more, which represents the same severity of symptoms as patients found to have ETD in the study by McCoul et al. However, only less than $10 \%$ of the patients enrolled had an abnormal tympanogram (type B or C) confirming the diagnosis of ETD. A clear weakness of ETDQ-7, in turn, is that it cannot discriminate between patients with obstructive ET dysfunction and patulous ET. Therefore, it cannot be used as a sole criterion for the diagnosis of ETD. For these reasons we are not able to generalize the results of this study to ETD. We can only talk about the effect of inferior turbinate procedure on patients' symptoms suggestive of ETD.

All clinical examinations and operations were performed by the same physician, who was not blinded to the patients' groups. Unblinding of the examining physician could introduce unintentional bias by causing misinterpretation of data. However, the examination parameters used in this study were not based on the subjective evaluation of the examining physician. Parameters of tympanometry, unlike otoscopic appearance or Valsalva and Toynbee tests, are not based on the subjective evaluation of the examiner. 
That is why tympanometry was chosen to be the only objective examination method in this study. However, it is sometimes very challenging to make a confirmed diagnosis of ETD based on both patient-reported symptoms and signs of negative pressure in the middle ear in the form of abnormal tympanometry curves. In mild or fluctuating cases, the patients may have symptoms suggestive of ETD but their tympanometry curves can be within normal limits.

\section{CONCLUSION}

The improvement of ETD-related symptoms due to surgery of the anterior half of the inferior turbinate was found to be equal to placebo. The findings of this study do not support the use of reduction of the anterior half of the inferior turbinate as a sole procedure intended to treat the ear symptoms assessed by the ETDQ-7 questionnaire.

\section{REFERENCES}

1. Berger G, Gass S, Ophir D. The histopathology of the hypertrophic inferior turbinate. Arch Otolaryngol Head Neck Surg 2006;132:588-94.

2. Willatt D. The evidence for reducing inferior turbinates. Rhinology 2009;47:227-36.

3. Seibert JW, Danner CJ. Eustachian tube function and the middle ear. Otolaryngol Clin North Am 2006;39(6):1221-35.

4. McCoul ED, Anand VK, Christos PJ. Validating the clinical assessment of eustachian tube dysfunction: The Eustachian Tube Dysfunction Questionnaire (ETDQ-7). Laryngoscope 2012;122:1137-41. 
5. Poe DS, Abou-Halawa A, Abdel-Razek O. Analysis of the dysfunctional Eustachian tube by video endoscopy. Otol Neurotol 2001;22:590-5.

6. Doyle WJ, Seroky JT, Angelini BL, Gulhan M, Skoner DP, Fireman P. Abnormal middle ear pressures during experimental influenza A virus infection--role of Eustachian tube function. Auris Nasus Larynx 2000;27:323-6.

7. Ohrui N, Takeuchi A, Tong A, Iwata M, Nakamura A, Ohashi K. Allergic rhinitis and ear pain in flight. Ann Allergy Asthma Immunol 2005;95:350-3.

8. Stammberger H. An endoscopic study of tubal function and the diseased ethmoid sinus. Arch Otorhinolaryngol 1986;243:254-9.

9. Liu P, Su K, Zhu B, Wu Y, Shi H, Yin S. Detection of Eustachian tube openings by tubomanometry in adult otitis media with effusion. Eur Arch Otorhinolaryngol 2016;273:3109-15.

10. van der Avoort SJ, van Heerbeek N, Zielhuis GA, Cremers CW. Sonotubometry: eustachian tube ventilatory function test: a state-of-the-art review. Otol Neurotol 2005;26:538-43.

11. Smith ME, Tysome JR. Tests of Eustachian tube function: a review. Clin Otolaryngol 2015;40:300-11.

12. Van Roeyen S, Van de Heyning P, Van Rompaey V. Value and discriminative power of the seven-item Eustachian Tube Dysfunction Questionnaire. Laryngoscope 2015;125:2553-6.

13. Van Roeyen S, Van de Heyning P, Van Rompaey V. Responsiveness of the 7-item Eustachian Tube Dysfunction Questionnaire. J Int Adv Otol 2016;12:106-8. 
14. Straszek SP, Schlünssen V, Sigsgaard T, Pedersen OF. Reference values for acoustic rhinometry in decongested school children and adults: the most sensitive measurement for change in nasal patency. Rhinology 2007;45:36-9.

15. Grymer LF, Hilberg O, Pedersen OF, Rasmussen TR. Acoustic rhinometry: values from adults with subjective normal nasal patency. Rhinology 1991;29:35-47.

16. Tomkinson A, Eccles R. Comparison of the relative abilities of acoustic rhinometry, rhinomanometry, and the visual analogue scale in detecting chance in the nasal cavity in a healthy adult population. Am J Rhinol 1996;10:161-165.

17. Fisher EW. Acoustic rhinometry. Clin Otolaryngol Allied Sci 1997;22:307-17.

18. Stoikes NF, Dutton JM. The effect of endoscopic sinus surgery on symptoms of eustachian tube dysfunction. Am J Rhinol 2005;19:199-202.

19. Low WK, Willatt DJ. The relationship between middle ear pressure and deviated nasal septum. Clin Otolaryngol Allied Sci 1993;18:308-10.

20. Lazo-Sáenz JG, Galván-Aguilera AA, Martínez-Ordaz VA, Velasco-Rodríguez VM, Nieves-Rentería A, Rincón-Castañeda C. Eustachian tube dysfunction in allergic rhinitis. Otolaryngol Head Neck Surg 2005;132:626-9.

21. Bakhshaee M, Ardakani HP, Ghazizadeh AH, Movahed R, Jarahi L, Rajati M. Middle ear function in sinonasal polyposis. Eur Arch Otorhinolaryngol 2016;273:2911-6.

22. Deron P, Clement PA, Derde MP. Septal surgery and tubal function: early and late results. Rhinology 1995;33:7-9.

23. Gluth MB, McDonald DR, Weaver AL, Bauch CD, Beatty CW, Orvidas LJ. Management of eustachian tube dysfunction with nasal steroid spray: a prospective, randomized, placebo-controlled trial. Arch Otolaryngol Head Neck Surg 2011;137:449-55. 
24. Moche JA, Palmer O. Surgical management of nasal obstruction. Oral Maxillofac Surg Clin North Am 2012;24:229-37.

25. Civelek S, Ozçelik M, Emre IE, Cakir BO, Turgut S. Comparison of radiofrequency applied to the total inferior choncha with application to its anterior third. Auris Nasus Larynx 2010;37:589-93.

26. Schilder AG, Bhutta MF, Butler CC, Holy C, Levine LH, Kvaerner KJ, et al. Eustachian tube dysfunction: consensus statement on definition, types, clinical presentation and diagnosis. Clin Otolaryngol. 2015;40:407-11. 
Table 1. Eustachian Tube Dysfunction Questionnaire-7 (ETDQ-7) questions.

1. Pressure in the ears?

2. Pain in the ears?

3. A feeling that your ears are clogged?

4. Ear symptoms when you have a cold or sinusitis?

5. Crackling or popping sounds in the ears?

6. Ringing in the ears?

7. A feeling that your hearing is muffled? 
Table 2. Patients' characteristics.

\begin{tabular}{ll}
\hline Age (years), Mean (range) & $44(23-69)$ \\
Sex & \\
Male, No. (\%) & $42(58)$ \\
Female, No. (\%) & $30(42)$ \\
Allergic sensitization & \\
$\quad$ Yes, No. (\%) & $28(39)$ \\
No, No. (\%) & $44(61)$ \\
Technique & \\
RFA, No. (\%) & $20(28)$ \\
Diode laser, No. (\%) & $18(25)$ \\
MAIT, No. (\%) & $23(32)$ \\
Sham surgery, No. (\%) & $11(15)$ \\
Preoperative ETDQ-7 total score & \\
1.0-1.9, No. (\%) & $32(45)$ \\
2.0-2.9, No (\%) & $24(33)$ \\
3.0 or more, No. (\%) & $16(22)$ \\
\hline \hline
\end{tabular}


Table 3. Tympanometry results ( $\mathrm{N}=144$ ears).

\begin{tabular}{lll}
\hline & Preoperative & Postoperative \\
Abnormal tympanometry (B or $\mathrm{C})$ & & \\
Active treatment groups $(\mathrm{N}=122), \mathrm{No} .(\%)$ & $6(5)$ & $7(6)^{*}$ \\
Sham surgery group ( $=22), \mathrm{No} .(\%)$ & $1(5)$ & $0(0)^{*}$ \\
Tympanometric peak pressure (dPa) & & \\
Active treatment groups, median (IQR) & $-4.0(-15.0-14.0)$ & $-4.0(-15.0-2.0)^{* *}$ \\
Sham surgery group, median (IQR) & $-8.0(-16.5-16.3)$ & $-5.0(-16.5-14.5)^{* *}$ \\
\hline \hline & & \\
IQR = interquartile range (Q25-Q75) & & \\
$* *$ Not significant, Chi-squared test &
\end{tabular}


Table 4. Results of the ETDQ-7.

\begin{tabular}{|c|c|c|c|c|}
\hline \multicolumn{5}{|c|}{ All patients } \\
\hline & $\begin{array}{l}\text { Preoperative } \\
\text { ETDQ-7, Median } \\
\text { (IQR) }\end{array}$ & $\begin{array}{l}\text { Postoperative } \\
\text { ETDQ-7, Median } \\
\text { (IQR) }\end{array}$ & $\begin{array}{l}\text { ETDQ-7 change, } \\
\text { mean }(95 \% \mathrm{CI})\end{array}$ & $p$-value \\
\hline \multicolumn{5}{|l|}{ Procedure } \\
\hline $\begin{array}{l}\text { All active treatments, } \\
n=61\end{array}$ & $2.1(1.4-2.9)$ & $1.7(1.2-2.1)$ & $-0.4(-0.6--0.2)$ & $<0.001 *$ \\
\hline RFA, $n=20$ & $2.5(1.3-3.3)$ & $1.7(1.5-2.3)$ & $-0.4(-0.8--0.02)$ & $0.03 *$ \\
\hline Diode laser, $\mathrm{n}=18$ & $1.6(1.3-2.4)$ & $1.4(1.1-1.9)$ & $-0.3(-0.6-0.01)$ & 0.06 \\
\hline MAIT, $n=23$ & $2.4(1.6-3.3)$ & $1.9(1.3-2.4)$ & $-0.5(-0.9--0.2)$ & $0.006^{*}$ \\
\hline Sham surgery, $\mathrm{n}=11$ & $2.1(1.4-2.9)$ & $1.4(1.3-2.1)$ & $-0.5(-0.9--0.1)$ & $0.04 *$ \\
\hline \multicolumn{5}{|c|}{ Preoperative ETDQ-7 total score 2.0 or more } \\
\hline \multicolumn{5}{|l|}{ Procedure } \\
\hline $\begin{array}{l}\text { All active treatments, } \\
n=34\end{array}$ & $2.9(2.4-3.4)$ & $2.0(2.43 .4)$ & $-0.8(-1.0--0.5)$ & $<0.001 *$ \\
\hline RFA, $n=12$ & $2.9(2.6-3.7)$ & $2.1(1.6-3.4)$ & $-0.8(-1.4--0.2)$ & $0.02 *$ \\
\hline Diode laser, $n=7$ & $2.6(2.1-2.9)$ & $1.9(1.3-2.3)$ & $-0.7(-1.3--0.2)$ & $0.02 *$ \\
\hline MAIT, $n=15$ & $3.1(2.4-3.3)$ & $2.0(1.6-2.4)$ & $-0.8(-1.3--0.3)$ & $0.01 *$ \\
\hline Sham surgery, $\mathrm{n}=6$ & $2.8(2.1-3.6)$ & $2.1(1.7-2.6)$ & $-0.7(-1.4--0.02)$ & 0.08 \\
\hline
\end{tabular}

IQR = Interquartile range (Q25-Q75)

*Statistically significant, Wilcoxon Signed Rank test 